\title{
Embodied Movement Awareness: Articulating Structure \& Flow across and through disciplines
}

\section{Róisín O’Gorman}

This workshop was based on many years of movement practices in theatre (with a specialized focus on somatic movement). Furthermore, it was based in larger research concerns around engaging movement at all levels of teaching and learning - not just as a means of getting from a to b, but as an overlooked and undervalued epistemology. This work also moves across disciplinary boundaries and allows for rich transdisciplinary concerns to work together connecting individual sensibilities to larger socio-political issues. The workshop offered methods of movement research from two recent projects. One project linked theatre students with archaeology students and focused on embodiment of skeletal structures and local landscapes. The other project engaged students from across a wide range of disciplines along with young children, teenagers and adults alongside professional dancers in the Cork iteration of the Global Water Dances (https://globalwaterdances.org/) project which linked individual bodies of water to larger questions of global water ecologies and social justice.

The workshop offered a brief framework of these practices and epistemologies but the workshop was primarily a movement based exploration. A crucial point of introduction however, was that it is not about accomplishing some kind of virtuosic movement pattern which focusses on external aesthetics. Instead, somatic practices attune closely to one's direct bodily experience, so the movement can be quite small. It is imperative in fact that one doesn't override the potential for listening to one's own direct experience. So much of our education system trains us to overcome our bodily experiences as limitations; here the invitation was to consider another possibility. This meant that the participants who were tired or not feeling very well, could still participate to their full ability at that particular time. Those with more intention or energy moved and sounded in full voice. Lying still on the floor for as long as one needed was offered as an option which quite a few frazzled conference participants took up. Whether moving at full speed or resting, it is in the pausing, the space between the in breath and the out breath, that we integrate information, we take in what we need and release what we don't. Can we actually attend to when and where learning and transformation happen?

This workshop began with an introduction to the embodiment of our skeletal human structure and the flows of our fluid systems. We embodied bone as a living tissue and the range of qualities of our fluidity in order to articulate the full range of our expression, presence and embodiment. We considered the 
creative, vocal, and movement pathways that emerged for the individual and the group as a whole. We were still and we found a few ways to rock and roll; we curled up and danced as wide as the world. We acknowledged resistance but also found courage to explore new possibilities, enjoying the chance to get things moving, as well as soak in the pleasure of slowing things down. The workshop offered a space for each participant to find their own range of motion and rhythmical needs. In reflecting on our experience and thinking about ways to integrate it into our teaching philosophy and practices it is worth noting what one participant sent afterwards:

Dear Roisin, Thank you so much for the amazing and touching workshop - I still find it hard to put in words the physical transformation I experienced within an hour of movement!

Moving and attuning together to our physical structures we discovered some of the possibilities of an embodied awareness which has much to offer all learning situations. Movement of this kind can support teachers and students alike in fostering a deeper appreciation of our commonality and particularity. It is possible to put it into words, however, this is not something that is central to most curricula.
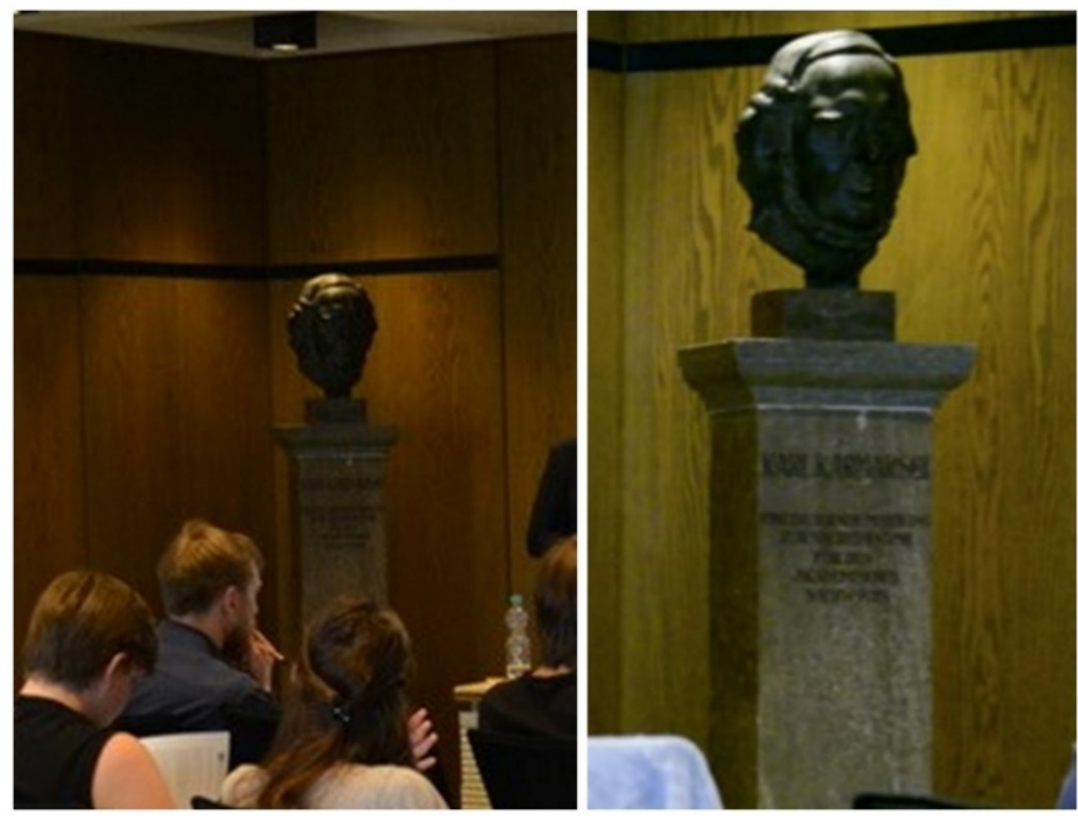

Figure 1: Karl Karmarsch, University of Hanover - Photo: Annalena Wilken

In the corner of the room of the House of Leibniz we used for my workshop for the conference, we had a silent participant, Karl, who was nonetheless very central to the proceedings. In the above image, Karl's presence hovers over room. People are sitting seriously, all in their places. It is a classical image of learning. Shh! Be quite - sit still. Of course, this mode has its place and can be comforting at the right times. However, the hovering bodiless head offered 
a clear counterpoint to the workshop which focussed on the elemental sense of playful movement that performative teaching and learning offers. Karl's serious silence held a place and obviated modes of being and thinking which institutions of learning prize.

Counter to this performative teaching and learning asks: What kinds of doings and undoing might movement awareness offer across the curriculum? How might we attend further to the micro and macro movements of learning? How can we become more aware of the intensive training in sitting that school requires and be aware of the role of movement and perception, and to take it further, aesthetics and pleasure, in our teaching and learning environments? To talk of aesthetics and pleasure in learning makes me feel uneasy as it disturbs learning as a serious endeavour which can be measured and commodified.

However, there was an overriding sense of pleasure both in the workshop and across the symposium as a whole. There may have been many circumstantial reasons for this, but there was an attention offered to the particularity of one's own learning alongside a building sense of a community of understanding, which offered some reprieve, some space to reflect and engage, that I experienced as enriching.

Back at home: near the library at UCC, which is called after him, another bodiless head-only man hovers:

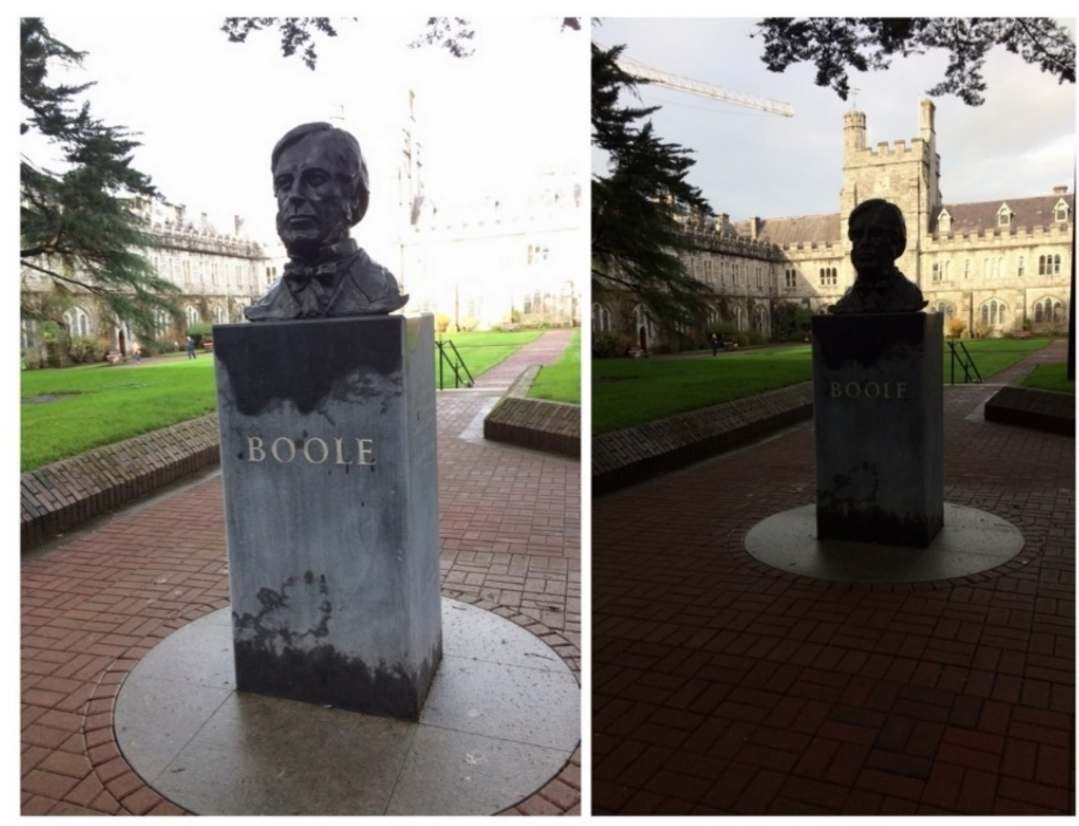

Figure 2: George Boole, University College Cork, Ireland - Photos: Róisín O'Gorman

We are always in the shadows of such figures. But perhaps, we can teach Karl and George to dance a little? Or perhaps, they were excellent dancers, and those facts were not remembered? Maybe it is that we need to remember that Karl loved the sound of music that wafted from an open window every Friday 
as he walked home, and it made him sway or spin; or how have we forgotten that George was light on his feet and it was at that weekend ball when choosing certain dance partners and rejecting others that his formulas began to click into place. If these 'scenes' are a possibility, those attributes are not foregrounded in these statues that remind us what the central values of our institutions are. Perhaps we can add other attributes to what those values are: [fill in your own reading here. ...

As statues of the once revered are being re-considered, and in some cases being dismantled in public spaces and universities the values that are taken as given are also being reviewed, dismantled, re-thought (for example the protests over statues in Charlottesville, North Carolina in the USA or at University of Cape Town in South Africa). Further, the gendered quality of such markers hardly needs further rehearsal, and yet, maybe it obviates why we are so stuck on that issue?

Performative teaching and learning expands the repertoire of what is possible. It challenges us to consider the processes of what is normalized by our institutions and to think about what other points of view are forgotten or what other moves are yet to be discovered. The challenge is how to articulate and represent those values in ways that are resonant and mobile rather than becoming further regimes to be followed and measured in prescribed ways. How can the performative remain performative when it becomes more central within our systems?

..... Your answers via email or postcard please.................. 